\title{
Telling the story of childhood cancer: an evaluation of the Discovery Interview methodology conducted within the Queensland Children's Cancer Centre
}

\author{
This article was published in the following Dove Press journal: \\ Patient Intelligence \\ 2 May 2016 \\ Number of times this article has been viewed
}

\author{
Penelope J Slater' \\ Shoni P Philpot ${ }^{2}$ \\ 'Queensland Children's Cancer \\ Centre, Lady Cilento Children's \\ Hospital, Children's Health \\ Queensland, ${ }^{2}$ Queensland Cancer \\ Control Analysis Team, Princess \\ Alexandra Hospital, Brisbane, QLD, \\ Australia
}

\begin{abstract}
This paper evaluates the process and impact of the Discovery Interview methodology developed in the National Health Service and applied in the Queensland Children's Cancer Centre. It shows how this methodology supports the family-centered care philosophy of the organization and gives staff insight into the experience of the families they care for. In total, 17 Discovery Interviews recorded during 2012-2014 were transcribed, deidentified, condensed, and read back to 222 staff in 20 different meetings. Families and staff involved in the process provided positive feedback. Over 53\% of staff found these sessions extremely valuable, and $46 \%$ rated them as valuable. Discovery Interviews were shown to be a powerful tool to engage with families and staff to improve the experience of families in the Queensland Children's Cancer Centre. The sessions where Discovery Interviews were read to clinical teams raised their awareness of the perspectives of families and impacted on the way they delivered care and interacted with families. Staff described the stories as insightful and valued hearing them and discussing ways to improve service, including individual clinical practice, service processes, and family supports.
\end{abstract}

Keywords: family experience, family-centered care, consumer engagement, service improvement, narratives

\section{Introduction}

The National Safety and Quality Health Service Standards were endorsed in 2011 with one of the ten standards being devoted to partnering with consumers with the aim of improving the responsiveness to consumer input and needs. ${ }^{1}$ In this context, the Queensland Paediatric Palliative Care, Haematology and Oncology Network (QPPHON) developed its consumer engagement strategy in 2012. It covered a range of strategies, including informing (handbooks, information sheets, newsletters, and Internet information for families), consulting (consumer feedback forms, Patient Experience Trackers, and surveys), involving (families speaking at workshops), collaborating (focus groups and planning workshops), and empowering (family membership of the Service Leadership Group and the development of a Patient, Family and Carer Network). ${ }^{2}$

The use of survey questions with responses on Likert scales had been used to gain family feedback in the service for many years. However, the responses were often difficult to interpret, and more information was required to clarify the real family needs. 
Where surveys allowed a written comment on the response, the families gave precise and personal feedback on issues that were important to them. This revealed an untapped resource of family input into improving their experience. The service commenced a search for a methodology that would be consistent with its vision of family-centered care and allow the families to have a significant voice in the future development of the service.

Increasingly, storytelling has become a means of bringing a full understanding of the patient/carers' experience to the service improvement table. ${ }^{3}$ The Discovery Interview methodology was a mechanism to obtain family feedback that reflected narrative methods, giving the interviewee control of the storytelling in the content and detail provided. ${ }^{4}$ It allowed families to give the feedback that was important to them, in their own words, and freely without the content of that feedback being controlled by structured questions. An evaluation of Discovery Interviews in the UK found a "remarkable level of passion and enthusiasm for the technique" and a positive impact on developing a family-centered culture. ${ }^{5}$

QPPHON became part of the Queensland Health Discovery Interview Collaborative in 2010. The purpose of this paper is to evaluate the Discovery Interview methodology as an engagement mechanism after 2 years of its use in the Queensland Children's Cancer Centre of the Royal Children's Hospital (RCH), Brisbane (now the Lady Cilento Children's Hospital), from the perspectives of the parents interviewed and the staff who heard and discussed the resulting transcripts.

\section{Methods}

Discovery Interviews were developed in the National Health Service in the UK in $2000^{6}$ as a service improvement tool and patient involvement mechanism in the development of patient-centered services. ${ }^{4,7,8}$ Generally, the approach uses one-to-one, face-to-face open interview techniques, with some prompting based on key stages of the experience of the service (a spine). ${ }^{8}$

Five QPPHON interviewers were trained through the Discovery Interview Collaborative in April 2011. One of the interviewers was nominated to be the coordinator and was trained in the deidentification and condensing of interview transcripts, relaying these stories to the clinical teams, and reporting on service improvement potentials.

Following approval by the RCH Human Research Ethics Committee, a total of 17 Discovery Interviews were recorded between March 2012 and May 2014. After responding to an expression of interest letter, interviews were collected from consenting carers whose child was admitted to the $\mathrm{RCH}$ with a diagnosis related to cancer management and treatment during 2010. In addition, consenting members of the QPPHON Patient, Family and Carer Network, which commenced in October 2013, were also interviewed. Interviewees were excluded if they were $<18$ years of age or had a cognitive impairment, intellectual disability, or a mental illness.

The interviews took place in the hospital in a quiet location or the family's home. The interviewee was taken through an information sheet and consent form, which was signed, and instructions given about how to revoke an interview from the pool. Interviews lasted anywhere between 30 minutes and 2 hours, as guided by the interviewee, and were audiorecorded. Interviews were transcribed, deidentified (patient, family, and clinicians), and condensed to enable them to be read back to clinical teams.

When Discovery Interviews were presented to teams, they were given a brief introduction to the methodology and reminded that the reason for collecting the interviews was to obtain detailed impartial family feedback and use it to improve the experience of families, not to speculate on the identity of the family or validate their experience.

After the Discovery Interview transcript was read in the session, discussion followed about the positive and negative aspects of the families' experience, how the experience could be improved, and anything the story triggered for the attendees about the care they provided to the families. The recommendations from these discussions were minuted to bring together the ideas for use in service improvement and planning.

The process and impact of Discovery Interviews were evaluated through a mix of qualitative and quantitative methods. Quantitative data were analyzed through Excel. Significant differences in survey responses were sought via a chi-squared test based on expected number of responses. Qualitative data were analyzed from interviews using an inductive thematic approach. The Discovery Interview methodology is not designed to provide a representative sample but to discover insights into the family's experience that cannot be gained in other approaches. Even one interview was a rich resource for the service team to develop service improvements.

\section{Parent feedback}

Feedback was compiled from several parents who spontaneously spoke within their interview about how they felt 
about the Discovery Interview process. These comments were collected at the time of interview.

\section{Evaluation of Discovery Interview sessions with staff \\ Staff session surveys}

All staff who attended a Discovery Interview session between January 2013 and May 2014 could complete an evaluation survey at the end of the session where they assessed whether the session had been extremely valuable, valuable, neutral, minimal value, or of no value. Chisquared goodness of fit test examined the distribution of responses.

\section{Detailed surveys of staff sessions}

Following three sessions, more detailed evaluations were completed by 34 staff to provide information on aspects of the process that were beneficial. These included the Oncology Education Meeting in August 2013 attended by nursing, medical, allied health, and research staff $(n=15)$; the Occupational Therapy Departmental Meeting in April 2014 (n=7); and the Shared Care Unit Regional Case Managers' Meeting in May $2014(\mathrm{n}=12)$. The questions asked were as follows:

- How do you rate the Discovery Interview session today?

- How valuable were the Discovery Interviews read today in raising your awareness of the perspective of our families?

- How valuable were the Discovery Interviews read today in impacting the way you personally deliver your care and interact with families?

- How valuable were the Discovery Interviews read today in giving you ideas about ways to improve our services?

- How valuable were the Discovery Interviews read today in making you think of ways we can improve our families' experience as a whole?

\section{Staff impact evaluation}

In May 2014, to determine the impact of the Discovery Interviews on staff clinical practice, the following questions were asked of all staff who had attended Discovery Interview sessions between January 2013 and March 2014.

- What impact did the Discovery Interview have on you?

- What has changed in your individual or team clinical practice as a result of hearing those stories? For example, what are you more mindful of, or how do you do things differently, when delivering the service?

- Any other comments or suggestions.
In all the comments received back from staff, any improvements arising from changes to clinical practice or through improvement projects were noted. Interviewers and the coordinator also reflected on the challenges and limitations of the methodology.

\section{Results}

\section{Parent feedback}

The general motivation of parents to consent to a Discovery Interview was to give back to the service or make things better for families that follow.

If we can help the next people in any way then, yeah, perfect.

So in some ways, if I can help out, I've got to. It's a bit of pay back somewhat - it's not much.

And I think that they need to know and people need to know that it's okay to say it, if they say it in the right way. Say, this happened and I don't really like it, or if they have an idea and they listen to you.

Going through their story, their feelings at diagnosis, the impact on the child and the family as a whole, and what the future holds was often an emotional process for parents, but one that they commented was therapeutic for them. For some parents, this was the first time they had gone through their story from start to finish and reflected on it. The Discovery Interview process facilitated this as it was conducted by an independent person, not involved in the child's care, yet who had the ability to influence the improvement of that care for that family's child and others to come. Some of the parents' comments were:

It's probably the first time I've really gone through it all. It's good to get it out and run through the process yourself, sort of remember a few things, put it all together a bit.

We have to talk about things to get it out of your system. And sometimes like, people at home, they get sick and tired of hearing about it, because it never goes away.

Some parents asked for a copy of their transcript so they could have a record of their story. These transcripts were provided with the content limited to the carer's story, excluding the interviewer content.

\section{Evaluation of Discovery Interview sessions with staff}

From January 2013 to May 2014, there were 20 sessions where Discovery Interview stories were read back to clinical teams with a total of 222 attendances ( 174 individual staff) 
Table I Number of attendances and meeting types involving Discovery Interviews at $\mathrm{RCH}$

\begin{tabular}{lll}
\hline Meeting & $\begin{array}{l}\text { Number of } \\
\text { meetings }\end{array}$ & $\begin{array}{l}\text { Total } \\
\text { attendees }\end{array}$ \\
\hline $\begin{array}{l}\text { Advanced Paediatric Oncology } \\
\text { Workshop }\end{array}$ & 10 & 82 \\
Oncology Allied Health Meeting & 1 & 11 \\
Oncology Service Leadership Group & 2 & 18 \\
Oncology Videoconference Series & 1 & 13 \\
Occupational Therapy Department & 1 & 12 \\
Staff Meeting & & \\
Regional Paediatricians' Workshop & 1 & 16 \\
Regional Case Managers' Workshop & 2 & 29 \\
Oncology Weekly Education Meeting & 2 & 41 \\
Total & 20 & 222 \\
\hline Abbriation
\end{tabular}

Abbreviation: $\mathrm{RCH}$, Royal Children's Hospital.

(Table 1), including 34 medical staff, 120 nurses, 54 allied health professionals, five administration/managers, and nine others. These also included staff from the ten regional Shared Care Units throughout Queensland during their annual workshops at $\mathrm{RCH}$.

\section{Staff session surveys}

Evaluation forms were completed by 130 staff who attended sessions, a response rate of 58\% (Table 2). In total, 53\% of staff who listened to these stories found them extremely valuable, and $46 \%$ found them valuable. This indicated a significantly positive response to the sessions $(P<0.001)$.

\section{Detailed surveys of staff sessions surveys}

The 34 staff who undertook the detailed evaluations rated "raising awareness of family's perspectives" the highest $(65 \%$ extremely valuable and 32\% valuable) (Figure 1). However, there was a significantly positive response to the sessions in all the dimensions measured $(P<0.001)$.

Some of the comments made by staff on the Discovery Interview process follow.

Fantastic insight into patient journey.

I loved hearing the story, very touching and informative. Provides insights and reminds us all. Also in planning for future needs.

Table 2 Number and percentage of responses regarding the Discovery Interview process where the session was evaluated

\begin{tabular}{lll}
\hline Response & Number & Percentage \\
\hline Extremely valuable & 69 & 53.1 \\
Valuable & 60 & 46.2 \\
Neutral & 0 & 0 \\
Minimal value & 1 & 0.7 \\
No value & 0 & 0 \\
\hline
\end{tabular}

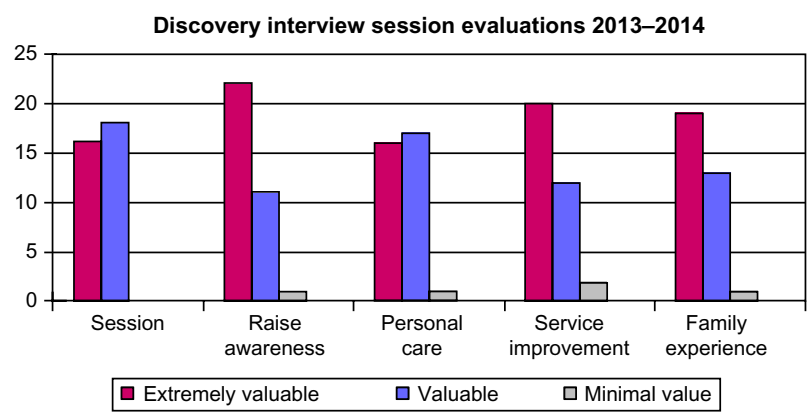

Figure I The number of responses by category to the five questions in the detailed evaluation.

Note: Except for one, the minimal value responses came from one responder.

A very unique insight into the experiences of children and families. Very powerful professional development opportunity.

The next highest scores were related to service improvement with $58 \%$ of staff finding the interviews extremely valuable in thinking of ways to improve families' experiences as a whole and $59 \%$ responding that they were extremely valuable in generating ideas to improve the service.

Some of the comments made by staff on the Discovery Interview process in relation to service improvement follow.

Though they ascribed meaning in hindsight, their perception is valued and valid and important around thinking of small things to do differently.

I enjoyed hearing the parent's stories and I think I will be more mindful of the parent's experience when treating oncology or complex care kids.

Continue to seek feedback from families re their needs to $[\ldots]$ ensure services are meeting these needs.

Overall, $47 \%$ of these staff found the interviews extremely valuable, and $53 \%$ valuable, in impacting the way they delivered care and interacted with families.

\section{Staff impact evaluation}

Seven staff from a range of medical, nursing, and administration participants of Discovery Interview sessions over 12 months from March 2013 were asked about the impact that the stories had on them, up to a year afterward. These were some of the responses.

It is so valuable to understand patient's frustrations and emotional journey as well as the physical. And also to remember that each patient journey is unique and has so many different factors contributing to their story. 
The Discovery Interview allowed us (the staff) to have insight into the very personal experiences of parents of children with a severe life threatening illness and the impact of their child's illness on the parents, their child and their family and their lives.

It also allows you to be more connected to the service you are providing and have an awareness of the part you play in their experience and their journey. You can gain an awareness that some of the little things you can do can make a big difference.

\section{Reflections on service improvements}

Various levels of improvements were gained from the Discovery Interview process from changes to individual clinical practice and attitudes of the listeners to service improvements brought out through changes in services, processes, and supports.

Individual or team clinical practice changes took place through the power of hearing the stories. For example, the responses below from the detailed evaluation surveys from staff showed how these insights had changed the responders' approach with newly diagnosed families, time taken to explain things clearly, and making decisions in the best interests of families.

How important those first meetings and conversations are, parents have reflected in detail how they were cared for, approached and spoken to, this has made me self evaluate my practice when meeting families in the first few days.

Listening to how parents feel overwhelmed after diagnosis when they meet multiple team members has made liaison nurses reevaluate, we meet families soon after diagnosis but are more mindful to balance with others also involved.

The interviews helped to remind me how important every exchange is between staff and patients. For us it may be another day at work, for patients it is a day in the path to their recovery. Every exchange could and does have meaning. It is so important to be mindful carers and take the time to listen carefully to what our patients have to say.

The staff commented on the value of the methodology as a service improvement tool:

I think the Discovery Interview process is one which should continue. Hearing them intermittently enables those opportunities to stop, take stock and reflect - these are things we don't always consciously take time to do.

The patient experience is so easily overlooked when it comes to caring for patients in busy wards and units. It is so valuable to hear their stories and remember who we are caring for.

Every time I hear a Discovery Interview there is always something to learn, I feel that we need to hear more of them, discuss themes and reflect and evaluate our practice to deliver the best possible care for our families.

Staff commented on the value of the Discovery Interviews in developing services in partnership with families:

Feedback to families that we value their engagement and contribution and will work in partnership to improve our practice, maybe relate some examples of this to families.

\section{Discussion}

The power of the stories provided through the Discovery Interview process was reflected in the value that staff placed on hearing them, and the insights that they gained from them. As the majority of health providers are motivated to provide good family care, the stories resonated with them as real experiences of people in their care, and they were motivated to reflect on their personal care provision and service processes that were impacting on the families.

Although not having the impact of the full transcript, extracts from the interviews were also used in various ways in the service to disseminate the stories as far as possible. Reading back several interview segments based on a theme was useful for some teams, for example, allied health services feedback provided to an allied health meeting, and end of treatment and regional care stories to the regional staff. Publishing extracts, one or two sentences long, from the interviews in staff news was also useful.

The interviews were sometimes used to support or inform other data. For example, feedback on how parents can be involved in avoiding clinical errors and how staff communicated errors were used in an Oncology Education Meeting where we discussed clinical incidents for the year. The Central Venous Access Device group also used extracts from Discovery Interviews related to the consistency of line care as viewed by the parents.

The Discovery Interviews provided a rich source of information from which service improvement could be gained. It was important to uncover and prioritize those areas that were most impacting, in partnership with families, and reflect together on how these needs could be best addressed.

The major themes from the interviews will be analyzed and service improvements developed through working groups and the Patient, Family and Carer Network members into 
action plans and tested through plan, do, study, and act cycles of improvement.

Children's Health Queensland supports the philosophy of family-centered care, "placing the needs of children, young people and their families at the heart of everything we do", including partnering with parents and carers. Discovery Interviews are an ideal tool for engaging families and staff to facilitate family-centered care in the various ways it may be defined. For example, in a comparison of the principles of family-centered care developed by several American bodies, ${ }^{9}$ all included partnership and collaboration with families and developing policies and practices alongside families to address their needs. The Discovery Interview methodology supports these principles. A study of perceptions of familycentered care in two Australian tertiary pediatric hospitals found a high score related to staff understanding what the family was going through. ${ }^{10}$ In this evaluation, there were repeated comments from staff that Discovery Interviews raised their understanding of the family's experience. Pediatric nurses in New South Wales supported family-centered care although there were some challenges in empowering families as the nurses wanted to preserve their role as knowledge experts in clinical practice. ${ }^{11}$ The Discovery Interview methodology overcomes this concern, as the families are the content experts on their experience. The staff at the $\mathrm{RCH}$ valued the family's perspective delivered in this way and allowed it to inform their clinical practice.

Although telling the story of their experience may cause distress to parents, this was natural and was minimal in contrast to the distress caused by the actual experience. The literature suggests that providing an opportunity for families to talk about their child's cancer experience can enhance psychological well-being. ${ }^{12}$ For example, bereavement research has found a therapeutic benefit for participating parents, and telling their story to others actually provides support in the social context. ${ }^{13,14}$ The parents in this study commented that telling their story benefited them in various ways, including being able to help others in the same situation and giving back to the service.

Storytelling is a familiar mechanism for people to exchange information in a meaningful and memorable way. ${ }^{4}$ In the Discovery Interview process, the parents told their story in their own way, in as much depth as they felt comfortable with, and had complete control over the content of the story. Thus, the carers relayed experiences that were important to them and provided a range of information beyond questions that the service might identify as areas to explore. The methodology obtained a broad range of detailed feedback along the entirety of the family experience with health care, which went well beyond family feedback that might be reported via a complaint or compliment mechanism, often related to one incident.

The reading of Discovery Interview transcripts to service teams provided an opportunity for reflection and the development of innovations for service improvement with the goal of ensuring a good family experience. Further thematic analysis of the interviews will allow the service to prioritize improvements in collaboration with our families.

The most common word used in the feedback on the Discovery Interview process by staff was "insightful". Discovery Interviews were a powerful means of consumer and staff engagement. It engaged staff as it linked with the purpose of their work and was relevant to their everyday practice. Staff learnt through applying relevant feedback to their care of families.

The stories relayed to the staff the realities of the family's circumstances, for example, the difficulties of the timing of coming to the tertiary center from regional areas, the impact of arriving at the oncology inpatient ward or the day unit for the first time, and becoming familiar with the ward environment and "rules". What was considered routine by our staff was often very confronting for families, especially those entering the service for the first time. Discovery Interviews formed a link between staff and families so these issues could be addressed.

The staff were often emotionally moved as they heard the stories of the families they cared for every day. The stories raised awareness of the family's perspective and helped staff better understand how the families were feeling at different points in their care journey. This impacted on their individual practice and, as staff brainstormed how to make the experience better for families, suggestions for service improvements were initiated.

Similar impacts have been shown in other studies. One study used an experience-based design process and worked with patients to redesign services based on feedback provided through narratives. It reported that the narratives had the power to "really captivate staff and retain their interest and energy throughout". Staff were inspired through the codesign of services, building relationships with consumers, and focusing on feedback on the care provided. ${ }^{15}$ Other studies reported that Discovery Interviews helped staff understand more fully what it was like to be a patient or carer in their service and placed them at the center of service development activities. ${ }^{7}$ Discovery Interviews were also memorable and insightful for staff and had a long-term 
impact, both in raising awareness and stimulating ideas for change. ${ }^{4}$

Discovery Interviews are now being used in various services in Queensland Health. For example, the Princess Alexandra Hospital gained insights into empathetic relationships between type 2 diabetes patients and their health providers. ${ }^{16}$

There are challenges in the methodology. Each interview required a great deal of effort and time to collect, transcribe, deidentify, condense and read back to the clinical teams, and develop resulting service improvements. It was a laborintensive process, but one that was balanced by the richness of information gained and the direct relevance to families of resulting service improvements.

As with any consumer feedback, it provided point in time information driven by the state of mind of the interviewees on the day, their capacity to share their experience, and the stage of treatment of their child. The interviewees may be feeling secure and strong enough to talk about their experience or they may be feeling too vulnerable due to their current circumstances, for example, with an upcoming scan or relapse or death of a patient known to them. Most of the interviews conducted for this study were of parents whose child had completed treatment, so this may have resulted in an emphasis in the stories toward the later stages of treatment, although important points of the experience seemed to remain vividly in the memory of the parents.

The environment in which the interview was conducted and the perceived power differential with the interviewer may have impacted on the level of sharing that took place. An observation by the interviewers was that when families were interviewed in their own home, as opposed to the hospital, the storytelling process was often more relaxed and conversational, perhaps reflecting the reduction of the power differential perceived by the parent.

The coordinator read the transcripts back to the clinical teams. It could be argued that this would not have the same emotional impact as the story being told by the interviewee, who lived the experience, or an actor. However, it also allowed the listeners to concentrate on the content of story rather than showing empathy toward the person telling the story. Regardless, the staff were often moved and motivated to improve the family experience.

This study used Discovery Interviews in the context of children's cancer where the carers told the story on behalf of themselves, their child, and their family. This limited the information to the perspective of the interviewee, and although the approach has provided valuable feedback to the service, it would be useful to expand the interviews to the patients themselves.

The ethics approval, and the Discovery Interview process itself, limited the sharing of actual full written transcripts with staff. Staff felt that this constrained the maximum use of those stories. However, the family confidentiality was protected by not allowing these transcripts to be scrutinized, and the adjunctive methods detailed earlier of sharing parent experiences counteracted this limitation.

Unpacking the issues brought up in Discovery Interviews to meet the family's needs must include the engagement of consumers in the redesign of our services ${ }^{14}$ and our Patient, Family and Carer Network provides us with an ideal group to work with. The codesigning of services with the patients/ carers' involvement is an avenue where consumers can teach staff how to design services for the whole human experience. $^{3}$

The next step in the use of the Discovery Interview methodology in QPPHON is to embed it as an ongoing strategy in engaging our consumers. We are planning the expansion of the interviews with families who are receiving care from the palliative care service, and with the older patient group. Staff place enormous value on hearing the stories of the families, and there is a huge potential in these interviews to gain the information we need to provide an optimal family experience through the difficult journey of childhood cancer.

It is also planned to use the methodology with staff to delve into their engagement and satisfaction, including coping strategies, during their service in children's cancer. This will provide a foundation of information to start an open discussion regarding staff satisfaction, which continues to be positively linked to improving patient-centered care. ${ }^{17}$

Discovery Interviews were shown to be a powerful tool to engage families and staff to improve the experience of families in the Queensland Children's Cancer Centre. The sessions where Discovery Interviews were read to clinical teams raised their awareness of the perspectives of families and impacted on the way they delivered care and interacted with families. Staff described the stories as insightful and continue to value hearing them and discussing ways to improve our service, including individual clinical practice, service processes, and family supports.

\section{Acknowledgments}

The abstract of this paper was presented at the Children's Health Queensland Research Day as a poster presentation with interim findings. Thank you to the 17 parents of children with cancer who provided such generous and open 
contributions in sharing their story. Thank you also to the interviewers and staff for listening.

\section{Disclosure}

The authors report no conflicts of interest in this work.

\section{References}

1. Australian Commission on safety and quality in health care [webpage on the Internet]. National Safety and Quality Health Service Standard 2: Partnering with consumers. Sydney: ACSQHC; 2016. Available from: $\mathrm{http}$ //www.safetyandquality.gov.au/our-work/patient-and-consumercentered-care/national-safety-and-quality-health-service-standard-2partnering-with-consumers/. Accessed February 2, 2016.

2. International Association for Public Participation, Australasia [webpage on the Internet]. Quality Assurance Standard for Community and Stakeholder Engagement. Wollongong, NSW: iap2;2015. Available from: http://www.iap2.org.au/resource-bank/command/download_file/ id/242/filename/PROOF17_1506_IAP2_QAS.pdf. Accessed February 2, 2016.

3. Bate P, Robert G. Experience-based design: from redesigning the system around the patient to co-designing services with the patient. Qual Saf Health Care. 2006;15(5):307-310.

4. Wilcock PM, Brown GCS, Bateson J, Carver J, Machin S. Using patient stories to inspire quality improvement within the NHS Modernization Agency collaborative programmes. J Clin Nurs. 2003;12(3):422-430.

5. Matrix Consultancy. Coronary heart disease collaborative evaluations of discovery interviews: final report. London: Matrix; 2005.

6. Bateson J, Brown GCS, Wilcock PM, Carver J, Machin S. Using patient stories to inspire quality improvement within the modernization agency collaborative programmes. J Clin Nurs. 2003;12:1-9.

7. Bridges J, Gray W, Box G, Machin S. Discovery Interviews: a mechanism for user involvement. Int J Older People Nurs. 2008;3(3):206-210.
8. NHS Improvement. [webpage on the Internet] Learning from patient and carer experience. A guide to using Discovery Interviews to improve care. Leicester, UK: NHS Modernisation Agency; 2003. Available from: https://www2.rcn.org.uk/downloads/professional_development/ mental_health_virtual_ward/treatments_and_therapies/chd-discoveryinterviewspdf.pdf. Accessed April 14, 2016.

9. Kuo DZ, Houtrow AJ, Arango P, Kuhlthau KA, Simmons JM, Neff JM. Family-centered care: current applications and future directions in pediatric health care. Matern Child Health J. 2012;16(2):297-305.

10. Gill FJ, Pascoe E, Monterosso L, et al. Parent and staff perceptions of family-centered care in two Australian children's hospitals. Eur J Pers Cent Healthc. 2014;1:317-325.

11. Paliadelis P, Cruickshank M, Wainohu D, Winskill R, Stevens H. Implementing family-centered care: an exploration of the beliefs and practices of paediatric nurses. Aust J Adv Nurs. 2005;23(1):31-36.

12. Helgeson VS, Cohen S. Social support and adjustment to cancer: Reconciling descriptive, correlational, and intervention research. Health Psychol. 1996;15(2):135-148.

13. Dyregrov K. Bereaved parents' experience of research participation. Soc Science Med. 2004;58(2):391-400.

14. Hynson JL, Aroni R, Bauld C, Sawyer SM. Research with bereaved parents: a question of how not why. Palliative Med. 2006;20(8): 805-811.

15. Pickles J, Hide E, Maher L. Experience based design: a practical method of working with patients to redesign services. Clin Gov: Intern J. 2008; 13:51-58.

16. Cotugno JD, Ferguson M, Harden H, et al. "I wish they could be in my shoes": patients' insights into tertiary health care for type 2 diabetes mellitus. Patient Prefer Adherence. 2015;9:1647-1655.

17. Luxford K, Safran DG, Delbanco T. Promoting patient-centered care: a qualitative study of facilitators and barriers in healthcare organizations with a reputation for improving patient experience. Int $J$ Qual Health C. 2011;23(5):510-515.
Patient Intelligence

\section{Publish your work in this journal}

Patient Intelligence is an international, peer-reviewed, open access journal that characterizes and measures the central role of patient behavior and intention in optimizing healthcare management in all areas of disease and complaint types. An improved understanding of patient intelligence coupled with predictive analysis helps an organization contribute more

Submit your manuscript here: http://www.dovepress.com/patient-intelligence-journal

\section{Dovepress}

effectively to achieving better outcomes. The journal is characterized by the rapid reporting of reviews, original research, methodologies, analytics, modeling, clinical studies and patient surveys across all disease areas. The manuscript management system is completely online and includes a very quick and fair peer-review system. Visit http://www.dovepress.com/ testimonials.php to read real quotes from published authors. 